\title{
A Pragmatic Approach for Implementing Knowledge Management in Pakistani Organizations using Open Source Technologies
}

\author{
Muhammad Anwar-ur-Rehman Pasha \\ Faculty of Computing and Information Sciences \\ Imperial College of Business Studies, Lahore,
} Pakistan

\author{
Shaheen Pasha \\ Division of Education \\ University of Education, Lahore, Pakistan
}

\begin{abstract}
In today's world, knowledge management is considered as a key to organizational growth and competitiveness. Pakistan is among those developing countries where the importance of knowledge management has been realized but its practices have failed to get sufficient attention. This paper has presented a pragmatic approach to answer the research question how Pakistani organizations can implement technology driven KM initiatives to enhance their productivity and competitiveness. Free and Open Source Technologies based a recursive framework for a phase-wise KM implementation has been proposed. Six key factors have also been identified to make KM initiative successful. Recommendations have also been made to make KM implementation smooth and effective.
\end{abstract}

\section{General Terms}

Knowledge Management, KM Frameworks, Knowledge Processes, KM Technologies, Free \& Open Source KM Technologies, KM in Organization

\section{Keywords}

Knowledge Management, Knowledge Processes, Knowledge Management Technology, Knowledge Management Factors, KM in Pakistani Organizations

\section{INTRODUCTION}

In recent years, knowledge has emerged as a driver of innovation, productivity, sustainability, economic growth and a key commodity of knowledge economies in which the generation and the exploitation of knowledge has started playing a predominant role in wealth creation. In parallel, globalization, liberalization, outsourcing and service orientated industry have brought structural changes in organizations and business processes which have modeled new challenges for organizations [1, 2, 3]. Many such changes and challenges have portrayed the role of knowledge management (KM) increasingly important for organizations' sustainability and competitiveness $[4,5,6]$.

$\mathrm{KM}$ is not just collecting knowledge artifacts. It is a multifaceted theme involving concepts like contextualization, socialization, externalization, combination, internalization, etc. [1, 2, 7]. Many successful implementations of $\mathrm{KM}$ at global level, like British Petroleum, Buckman Laboratories, Shell, Hewlett Packard, Microsoft, Xerox, etc., urge other organizations to develop their own KM system for capturing, distributing, sharing, preserving, and securing, their knowledge assets in order to stay ahead of their competition $[8,9]$.
Pakistan is among those developing countries where the importance of KM has been realized but its practices have not acquired sufficient attention. Lack of awareness about $\mathrm{KM}$ technologies and associated processes are among some common problems reported in recent studies $[10,11,12$, 13]. Also, the complexity involved in KM implementation and the discouraging results reported in research like about $84 \%$ of knowledge management projects fail [14] make many Pakistani managers reluctant to implement technology based KM in their organizations [3].

This study has suggested a pragmatic approach for Pakistani organizations to handling both ontological and epistemological aspects of KM. The proposed approach is less expansive and offers multifold benefits includinga smooth transition towards technology driven KM. However, the awareness of the existing technologies and key concepts of KM has to be promoted at all levels. Hence, the study aims to advance the understanding of the key concepts of $\mathrm{KM}$ and the relationship between available technologies and Knowledge Processes (KPs) so that the management of Pakistani organization could adopt, in place of developing a customized KM system, a more pragmatic approach for implementing technology driven KM.

The paper is structured in eight sections. The methodology of the study is discussed in the next section. The key concepts of $\mathrm{KM}$ including knowledge, the classification of knowledge, knowledge management and knowledge processes are discussed in section $3,4,5$ and 6 respectively.Section 7 describes the theoretical framework for the implementation of a technology driven $\mathrm{KM}$ in Pakistani organizations. The conclusion $\&$ recommendations are given in the last section.

\section{RESEARCH METHODOLOGY}

Applying content analysis methods [15], research papers, technical reports and casestudies published in research journals have been reviewed to examine the key concept of $\mathrm{KM}$ and its relationship with technology. The findings are synthesized and presented in the form of key factors which are important to implement an effective KM. Also a review of open source technologies has been carried out to recommend appropriate technologies to encourage managers to take technology driven $\mathrm{KM}$ initiatives in their organizations.

\section{WHAT IS KNOWLEDGE?}

The word "knowledge" takes on a variety of meanings within everyday language, within specific fields, and even within the same disciplines. For example, Alavi and Leidner [16] consider knowledge as a state of knowing and understanding. McQueen [17] \& Carlsson, et al. [18] 
consider knowledge as an object that can be explicated, stored and manipulated. Wilson [19] \& Zack [20] talk about its context sanative nature which means knowledge provides different meanings depending on the context. Andriessen [21] has pointed out at least 22 different metaphors used for knowledge. Such efforts broadly revolve around two key questions "What is it possible to know?" (Ontology) and "How can we be certain of what we know?" (Epistemology). Yet the problem of locating knowledge and finding out who has what kind of knowledge remains as a human mind usually has knowledge of many things. Even if knowledge can be located, the problem of determining who needs what knowledge, and when, stays [22]. Many such dimensions of knowledge need further exploration.

In this paper we have followed Davenport and Prusak's [2] point of view that knowledge is a fluid mix of framed experience, values, contextual information, and expert insight that provides a framework for evaluating and incorporating new experiences and information. It originates and is applied in the minds of knower. Davenport and Prusakhave address cultural components of organizations including individuals' experiences, embedded routines, processes, practices, and norms. However, Nonaka [23] and Huber [24] have considered knowledge as a justified personal belief that increases an individual's capacity to take effective action such as problem solving.

\section{CLASSIFICATION OF KNOWLEDGE}

Researchers from different domains have viewed knowledge from their own perspective and have explored its dimensions accordingly. For example, some scholars classify knowledge as: logical, semantic, systemic, and empirical. Other classifies knowledge as: personal, procedural, and declarative or prepositional. Greek philosopher Aristotle as discussed in [25] - classifies knowledge as: i) EpistemeKnowledge: abstract generalization which is the basis of science, scientific laws and principles, ii) TechneKnowledge: technical know-how, iii) Prognosis-Knowledge: practical wisdom drawn from social practices, and iv) MetisKnowledge: searches for a practical solution which is opposite to metaphysics.

The topic of knowledge classification has also been discussed by religious scholars as well. Osama [26] has reviewed the thoughts of many Muslim scholars starting from al-Kindi in the ninth century to Shah Waliallah of Delhi in the eighteenth century who have discussed this topic. Osama also reviewedthe ideas of three other Muslim thinkers - al-Farabi (870-950 AD), al-Ghazzali (1058-1111 AD) and Qutb al-Din al-Shirazi (1236-1311 AD). Scholars from other religions like Christianity, Buddhism, Hinduism, etc. have also explored this topic. As the classification of knowledge is a multifaceted topic we will restrict onto $\mathrm{KM}$ track only.

Polanyi [27] classifies human knowledge into explicit which is in codified form and tacit knowledge which is personalized and deeply rooted in action, commitment, and involvement in a specific context. Polanyi's thoughts were taken up by Ikujiro Nonaka $[1,23]$ in explaining the theory of organizational knowledge creation. However, Botha, et al. [28] suggest that both types of knowledge should be seen as a spectrum rather than as definitive points.

The debate of knowledge classification is not over yet. Alexander \& Judy [29] distinguish three types of knowledge: i) declarative, ii) procedural, and iii) conditional. de Jong \& Ferguson-Hessler [30] classify knowledge as situational, conceptual and strategic. They also made a distinction between domain specific and general knowledge. Some researchers talk of embedded knowledge which resides in systemic routines [31]. Badaracco [32] explores the notion of embedded knowledge within the context of individuals' relationships and material resources. Blackler [33] expands on a categorization of knowledge that was suggested by Collins [34]: embrained, embodied, encultured, embedded and encoded. de Jong \& FergusonHessler [30] discuss about "depth of knowledge" which refers to the extent that knowledge is "firmly anchored in a person's knowledge base and external information has been translated to basic concepts, principles, or procedures from the domain in question" (p. 107). The concept of depth of knowledge is associated with 'surface' versus 'deep' where deep knowledge is associated with cognitive abilities like comprehension, abstraction, evaluation and critical judgment while surface knowledge is associated with rote learning, reproduction, and trial and error [30].

Despite these variations, in this paper we have followed Polanyi's path and believe that organizational knowledge is a mixture of tacit and explicit elements. Explicit knowledge refers to codified form of knowledge available in manuals, official documents, memos, etc. while tacit knowledgeis a non-codified form of knowledge resides in people mind, organizational culture, communities of practices, operative routines, etc.

\section{KNOWLEDGE MANAGEMENT}

The term 'knowledge management' got recognition in the 1980s [35] due to the emerging concerns of organizations regarding the increasing role of knowledge in organizational sustainability [36]. Alavi and Leidner[16] define KM as a systematic and organizationally specified process for acquiring, organizing, and communicating both tacit and explicit knowledge of employees so that other employees may make use of it to be more effective and productive in their work. This definition misses the human dimension. Nonaka \& Takeuchi [1] consider KM as a form of managements' expertise which draws out individuals' tacit knowledge and makes it explicit and accessible for all employees to improve organizational performance. Talking about the importance of KM Afiouni [37] states, "knowledge management (KM) has become a must to ensure organizational effectiveness". As yet there is no agreed upon definition of KM, but its importance has been recognized globally. In his study, Prusak [38] reports that approximately $80 \%$ of 1000 global businesses have initiated their knowledge projects and approximately $68 \%$ of themare underway.

KM has three major components: (i) People who create, share and use knowledge, (ii) Processes which offer methods to acquire, create, organize and transfer knowledge, and (iii) Technology which provides mechanisms to store and provide access to data, information and knowledge created by people [39]. People-track primarily involved in assessing, changing and improving human individual skills and/or behavior and believes employees' brainpower as a true asset of an organization. They advocate that technology should be considered just an enabler; enabling organizations to execute knowledge processes (KPs) [40, 41]. The process-track people consider knowledge as a collection of processes which are constantly changing like employees' skills, know- 
how etc. and traditionally involve in learning and managing these skills. The technology-track people are involved in the construction of computer systems. To them knowledge is a collection of objects that can be identified and handled through the latest technological advancements including software, the Internet, databases, etc. Apart from these differences, in today's world an effective KM involves people, processes and technology.

\section{KNOWLEDGE MANAGEMENT FRAME WORKS \& KNOWLEDGE PROCESSES}

For the implementation of Knowledge Management, in literature, various knowledge management frame works and associated knowledge processes have been proposed. Nonaka and Takeuchi's [1] framework contains two dimensions: ontological and epistemological. The ontological dimension relates to the interaction between tacit and explicit knowledge whereas the epistemological dimension views individuals as the key source of knowledge creation. These two dimensions constitute the four key knowledge processes: Socialization, Externalization, Combination, and Internalization. Tannembaum and Alliger's [42] framework sees KM from a more static perspective and defines four KPs: Knowledge Sharing, Knowledge Accessibility, Knowledge Assimilation, and Knowledge Application.

This variation of thoughts is very natural as in the last few years KM research and practices have grown at a dramatic pace. As a result KM literature is fragmented. Different KPs have been proposed in different KM frameworks. For example, Rastogi [43] advocates that for meeting KM requirements, organizations need toimplement the following processes: Identification, Mapping, Capturing, Acquiring, Storing, Sharing, Applying, and Creating, Generating or Discovering new knowledge. In place of this static hierarchical structure, Probst [44] perceives KM as an evolving process. He proposes eight KPs that form two cycles: Inner cycle and Outer cycle. The inner cycle is composed of: Identification and Acquisition. The outer cycle composed of: Development, Distribution, Utilization and Preservation, Knowledge Goals and Knowledge Assessment. Heisig, et. al. [46] also consider KM as a dynamic process. Their model has some similarities with the inner cycle of Probst's model. They have proposed four processes: Create, Store, Distribute, and Apply.

McElroy [47], working with other members of KM Consortium International, defines a KM framework called "The knowledge life cycle". Their framework assumes that knowledge creation is preamble beforeknowledge can be captured, codified and shared. They have defined two key KPs: Knowledge Production \& Knowledge Integration. Their framework has introduces two new concepts: Supply Side which deals with the supply of existing knowledge to or from workers and Demand Side which focuses on the supply of existing knowledge to a workforce.They believe that through developing a range of interventions aiming at supporting, strengthening, and reinforcing employees' knowledge related patterns of behavior can create a strong impact on organizations' capacity to produce and integrate knowledge.

A KM frame work developed by Arthur Anderson and APQC [48] proposed a set of eight KPs: Applying, Sharing,
Creating, Identifying, Collecting, Adapting, and Organizing. Demarest's framework [49] divides KPs into Construction, Embodiment, Dissemination, and Use. Little's framework [50] proposes five KPs: Acquisition and Creation, Saving, Disseminating, and Use. Delphi's framework[51] proposes four key KPs: Capturing, Sharing, Leveraging and Feeding. In his KM framework, Wijnhoven [52] categorizes KPs into Acquisition, Retention, Search, Maintenance, and Dissemination. Pan and Scarbrough's framework [53] proposes five KPs: Knowledge generation, Processing, Storage, Dissemination, and Use/Reuse. The KM framework proposed by Lee and Kim [54] advocates for three KPs; Accumulation, Integration, and Reconfiguration. Some other studies which discuss the topic include Kucza [22], Alavi \& Leidner [16], Bhatt [55], Lee and Choi [56], McInerney \& Koenig [57].

The above discussion shows that the concept of KPs varies among different KM frameworks that may be due to the context in which they have perceived KM. However, KPs appears to be the backbone of KM. The knowledge processes which this study have concluded important for an effective KM are defined in sub-section 7.4.

\section{THE PROPOSED KM FRAMEWORK}

We have discussed various KM frameworks in the previous section. These frameworks mainly focus on KPs and consider them as a primary factor for an effective KM. We also realize the importance of KPs, yet we believe the success of a KM initiative depends on many other factors as well. The proposed framework has identified six key factors for making a KM initiative successful: i) Organization Structure \& Management, ii) Organizational Culture, iii) Reward System, iv) Knowledge Processes, v) People, and vi) Technology.

The proposed framework has some similarities with Gupta and Govindarajan's [58] framework which has identified six factors for an effective KM initiative: i) Information Systems, ii) Organizational Structure, iii) Reward Systems, iv) Processes, v) People, and vi) Leadership (p.71). However, the proposed framework has many differentiating features which make it more effective for Pakistani organizations than their framework. The distinctive features between both frameworks are explained here.

Firstly, the proposed framework has considered organizational structure and management two interrelated concepts which cannot be set apart. Secondly, in any competitive organization managers need to play a leadership role. Therefore, they are not considered discrete factors and are not handled separately. Thirdly, the proposed framework has taken technology in a broader sense not just information systems only. The latest developments of KM technologies and complexities involve in managing the burgeoning amount of available knowledge have made effective knowledge management unthinkable without adopting a broader approach [59]. In recent years new technologies have emerged in the market such as Web 2.0, neural networks, intelligent agents, data mining, genetic algorithms, fuzzy logic, conceptual retrieval, semantic net, etc. These technologies have given a new dimension to handling knowledge processes. Nevertheless, the majority of the organizations in Pakistan are not aware of such technologies which are hindering them to get the benefits of 
these technologies. For an effective implementation of KM, organizational management needs to be aware of these technologies. In the next sub-sections we will discuss about the key factors of the proposed framework.

\subsection{Organization Structure \& Management}

For an effective KM an effective organizational structure is very important. An organizational structure that supports the flow of knowledge regardless of employee role, job function, or other traditional boundaries is more permeable for knowledge based organization than a KM strategy. Knowledge based organizations are considered one of the key pillars of today's knowledge economies. Nonaka and Takeuchi [1] describe these organizations in terms of their ability to cope with the changing environment through creating new knowledge and embodying it into their routine practices. In another paper, McCampbell, et al. [60], define that "Successful companies are those that consistently create new knowledge, disseminate it widely throughout the organization, and quickly embody it in new technologies and products".

Organizations in Pakistan can be divided into three hierarchical levels: i) higher authorities that acts as leaders and devise organizational strategies, ii) middle managers who are in-charge of independent departments and work incollaboration/cooperation with other departments, and iii) the employees who work in different departments on different positions to perform routine tasks. For an effective $\mathrm{KM}$, organizational' vision, mission, goals and objectives must be made clear to people working at all levels. Equally important is a healthy cooperation and collaboration among all units to manage and exploit the available intellectual assets for maintaining competitive edge. Research has suggested that flexible organizational structure, effective strategies along with the implementation of appropriate technologies can make KM more practical and manageable [61].

Along with organization structure, effectivemanagement is the equally important. For a successful KM management needs to accept the leadership role $[43,2,62]$ as it is critical for creating organizational vision, mission, goals, objectives, and KM strategies. In Pakistani organizations this role of management becomes more crucial as people are usually reluctant to take any initiative due to the lack of ownership, motivation, fear of accountability, favoritism and organizational politics. Management can act as coaches and mentors and can demonstrate through their behavior and practices what $\mathrm{KM}$ could do to support organizational sustainability, productivity, and competitiveness. It is also imperative for top management to give due respect to the new ideas set forth by other employees. Doing so encourages creativity and motivation among organizational employees.

\subsection{Organizational Culture}

Organizational culture is an important factor reference to the implementation of an effective KM. According to Martin [63], the key to effective KM is to create an organizational culture that understands what knowledge is important, why that knowledge is important, and then offers processes to put that knowledge into action. However, it is commonly argued that implementing $\mathrm{KM}$ is not that difficult compare to convincing organizational people to stick with it. For this purpose, organizations need to create a culture which helps employees at all level to maintain their enthusiasm, belief and commitment to follow KPs in their routine practices. For developing such culture everyone must be clear about his/her role, key objectives and expectations from KM initiative. Equally important is the ownership of knowledge areas and KPs. Employees fell safe and become encouraged if the organization has well-defined standards and culture of fairness and accountability.

Communities of practice is an important element of organizational culture. These are informal groups that interact and collaborate regularly around work-related issues and challenges [64]. These communities are invaluable sources for knowledge sharing, discovery/detection, transfer, utilization, reuse and creation. Management need to provide appropriate technology support to such communities to gathering knowledge for widespread corporate use.

\subsection{Reward System}

The importance of a reward system has been acknowledged in many studies. An effective reward system motivates people for knowledge creation and sharing [2]. Organizations need to realize that much of invaluable knowledge resides in people's mind. This knowledge does not flow easily across functional boundaries or among individuals unless people are not encouraged to do so through an effective reward system that keeps their intrinsic and extrinsic motivation high [65]. It becomes more critical in Pakistani organizations where people are reluctant to transfer their expertise as they feel sharing/transferring of expertise may undermine their importance [3]. People are also reluctant to learn from others as they feel doing so may label them incompetent. Such cultural aspects could be overcome through an effective reward system including special bounces or promotions for activities like acquiring new skills, initiatingnew projects, accepting new responsibilities, contributing toward organizations' productivity, offering training to other employees [66]. Fair implementation of an effective reward system can provide assurance to the employees that they are still valuable even they have shared their knowledge with other employees. However, favoritism can undermine the whole system.

\subsection{Knowledge Processes}

In section 2 we have already discussed that KPs are the backbone of any KM initiative. Martin et al.[67], has defined some key purposes of KPs.

- Connect people for knowledge sharing.

- Connect people with knowledge repositories.

- Encourage knowledge creation.

- Allow knowledge encoding for easier transfer.

- Disseminate knowledge around the organization.

Some other purposes of KPs include maintaining organizational intellectual assets, promoting collaborative problem solving, streamlining employees' workload, optimizing performance, maintaining competitive advantages, etc. Although, the community has different views about KPs, we believe the selection of appropriate KPs can help organizations to achieve the required results. The proposed framework is based on the following KPs; yet they do not follow any hierarchical order.

- Knowledge Discovery and Detection: discovering knowledge that an organization possesses. 
- Knowledge Capture and Codification: capturing knowledge from various sources and converting it in a form that can be used for specific purposes.

- Knowledge Organization:classifying, mapping, indexing, and categorization of knowledge for navigation, storage, and retrieval.

- Knowledge Sharing: making the right knowledge or the right knowledge sources available to right people at right time.

- Knowledge Transfer: dissemination of knowledge from one part of the organization to another (or all other) part(s) of the organization or other organizational members.

- Knowledge Acquisition: acquisition of knowledge from human experts, books, documents, sensors, or computer files.

- Knowledge Verification: testing and adapting particular knowledge based on the situation in order to be suitable for the organization.

- Knowledge Utilization: applying knowledge to organizational functions.

- Knowledge Creation: generating and discovering new knowledge of any types. It also includes the conversion of tacit knowledge into explicit knowledge and vice versa.

- Knowledge Reuse: recalling that what knowledge has been stored, in what location, under what index or classification scheme and recognition that what knowledge meets the users' needs.

The proposed processes support a wide range of KM activities which are essential for an effective KM.

\subsection{People}

People are another important element of a KM initiative. Martin et al. [67] emphasis that organizations should consider people as one of its core values. However, persuading people to develop and promote a KM culture requiresan environment which appreciates employees' competence, promote teamwork, fuel motivation, and foster trust. Also, people need to be integrated into KM initiatives. It means that people must have a clear understanding of the philosophy, goals, objectives, strategy and benefits of the KM initiative. People need to be given a confidence that they are the right people for the organization and they are a valuable asset of the organization.These factors will greatly influence the level of knowledge shrining among individuals and within the organization as a whole. It also helps people to realize that $\mathrm{KM}$ is valuable both for them as well as for the organization.

For an effective KM initiative entire organizational population needs to know about knowledge resources, KPs, and operational skill of associative technologies. If any of these three are missing or under developed, the KM initiative may end up in a failure. The proposed framework suggests that management needs to realize that before performing a significant piece of work, people need to learn and to develop the required level of operational competency. Therefore, it is imperative for management to hire people whose main tasks include training people, coaching individuals with $\mathrm{KM}$ roles, monitoring $\mathrm{KM}$ activities, crafting the long-term KM strategy and making any interventions needed to sustain KM. The resources spent on such activities should be considered as an investment than expenditures as the key objective of this investment is to increase and exploit organizational knowledge to maintain competitive advantages. As Penrose [68] comments "This increase in knowledge not only causes the productive opportunity of a firm to change in ways unrelated to changes in the environment, but also contributes to the "uniqueness", of the opportunity of each individual firm". Similarly, Drucker [69] suggests "....making knowledge productive is a management responsibility. It cannot be discharged by government; but it also cannot be done by market forces. It requires systematic, organized application of knowledge to knowledge". The proposed framework suggests that the organizational management must accept the responsibility of making people valuable for the organization.

\subsection{Technology}

In today's world a successful KM could never be considered without the use of technology. Trend of technology usage is growing in Pakistan; however very few organizations have implemented KM. Abass, et al. [3] comment that the present societal culture in Pakistan does not support open sharing of knowledge as sharing of knowledge is considered akin to sharing of power. Although their study shows employees' positive perceptions towards $\mathrm{KM}$ practices but lack of employees' technology awareness limiting the use of technology for speedy knowledge sharing. Malik \& Malik (2008) identify the lack of appropriate technology infrastructure and other media which facilitate the codification, diffusion and transfer of knowledge. In his study "Critical Success Factors for Effective Knowledge Management in Corporate Sector (Pakistan)", Ali [11] concludes that the use of technology can encourage employees to participate in knowledge processes if their awareness \& technical skills are upgraded. Similarly, Bano[12] has acknowledged the importance of technology in terms of business process alignment and recommends promoting technology awareness among organizational employees for KM.

Multiple approaches of technology usage for KM activities have been reported in literature [7]. Some organizations develop their own customized knowledge management systems. Research has shown that not all such projects succeed. BenMoussa [70] reports that about $84 \%$ of KM projects fail. Some other technologies reported in the literature include knowledge portals, collaborative workplaces, knowledge directories, knowledge forums, knowledge servers and services, knowledge bases and trees, etc. Zack [20] has divided these technologies into two groups: integrative applications \& interactive Applications. Integrative applications exhibit a sequential flow of explicit knowledge into and out of the repository whereas interactive applications vary by the level of expertise between producers and consumers and the degree of structure imposed on their interaction. Recently, Web 2.0 has been used as effective KM technologies to facilitate creativity, interaction, collaboration, and sharing between users. Social-networking sites, social bookmarking, wikis, weblogs (blogs), podcasts, and folksonomies, social software, RSS feeds and web application programming interfaces (APIs) are some other examples of Web 2.0 technologies.

According to AMR Research [71], in 2007, American organizations spent $\$ 73$ billion on KM software, and KM spending is expected to grow nearly $16 \%$ to an average of $\$ 1,224$ per employee in 2008. Such figures create an impression that $\mathrm{KM}$ is an expensive venture; hence 
discourage Pakistani organization from initiating any $\mathrm{KM}$ venture.

In this perspective, the proposed framework suggests a more pragmatic approach for handling ontological and epistemological aspects of KM using the available Free and Open Source technologies. The framework has suggested a phase wise recursive implementation strategy which is more suitable for Pakistani organizations than developing a composite system. This will help the organizationsto save money and make a smooth transition towards technology driven KM. However, awareness of the existing technologies is much needed.The proposed phase wise recursive implementation strategy is discussed below:

- Phase 1 is the analysis of organizational needs and the existing system. For this purpose a knowledge management team should be formulated to perform the auditing, assessment and analysis of the existing technology infrastructure, organizational structure, business processes, communities of practices, culture, management approach, etc. The knowledge acquired in this phase will help to draw the blueprints of the KM initiative.

- Phase 2 covers tasks like the development of KM strategy related to KPs for performing routine task (tactical processes) and KPs for harnessing organizational goals (strategic processes), the selection of appropriates platform and technologies, ensuring the availability of human resource with appropriate skills and financial resources, etc. This phase needs an open commination between the management \& KM team. Review and fine tune the previous phase if required results have not been achieved.

- Phase 3 refers to the design and development of the new system. Formulation of a system development team with appropriate skill set is the most important aspect of this phase. An effective and open communication between KM team \& system development team is essential to make this phase successful. Review and fine tune the previous phase if required results have not been achieved.

- Phase 4 refers to the deployment of the newly developed system. This is the most tedious and crucial phase involves challenges like installation, training, coping with change, etc. A positive and encouraging role of management is very essential in this phase to overcome unexpected resistances \& challenges. Review and fine tune the previous phase if required results have not been achieved.

- Phase 5 is the evaluation phase which evaluates the system's performance and makes necessary changes. A strong feedback system has to be in practice to make this phase effective. Review and fine tune the previous phase if required results have not been achieved.

The successful execution of these phases will reflect the return of investment.

It is strongly recommended that the system development team should avoid developing a comprehensive KM system in one go. A fragmented approach will be more appropriate. For example, using a free and open source (FOSS) content management system a web portal could be developed for Knowledge Sharing, Knowledge Organization, Knowledge Creation, Knowledge Reuse, etc. It will also help to develop a web community which can develop their own forums for sharing their experiences, concerns and data. Through implementing blogging software, organization managers can provide the facility to run both internal and external blogs through which they can perform the role of mentors/guides. Through blogging facility individuals can share their success stories. RSS feeds can be integrated into an existing web portal to hook up the dynamic sections like press releases, technology updates, the latest developments, etc. Similarly, the implementation of local mail \& online newsletter can establish a social network to promote and share new ideas and products, to organize training and even to get advance feedback for underconstruction features.

The implementation of an open source wiki can be used for knowledge creation, knowledge updates, knowledge sharing. Different groups or individuals can manage their own area and periodically update its contents with new knowledge. Other group members can also validate the published knowledge. Open source database and data mining tools can be used for knowledge capturing, knowledge organization, knowledge transfer, knowledge discovery and knowledge reuse. Many other Web 2.0 tools can be integrated to make the $\mathrm{KM}$ initiative more effective.

\section{CONCLUSION \& RECOMMENDATIONS}

Since its recognition in the 1980s, after facing many critical objections, KM has reached to a point where it has been accepted as a strategy of competitive advantages. However, Pakistani organizations have failed to get benefits from its potential due to many reasons including organizational culture, lack of awareness, management apprehensions about KM, etc.

Although, KM community is divided in three groups: technology track, people track and process track, we believe a synergy of these three tracks along with open source technologies would be more appropriate for Pakistani organizations. Yet, organizations need to develop effective knowledge processes, to select appropriate technologies to support these processes, to provide adequate training to its employees, to devise an effective reward system and bring organizational structure and management role in-line with the KM strategy.

The study has discussed various KM frameworks proposed in recent literature. These frameworks mainly focus on KPs and consider them as a primary factor for an effective KM. The proposed frame also realizes the importance of KPs, yet it believes the success of a KM initiative depends on many other factors as well. The proposed framework identifies the following key factors which are important for making a KM initiative successful.The study has identified six key factors of an effective KM: (i) Organization Structure \& Management, (2) Organizational Culture (3) Reward system, (4) Knowledge Processes, (5) People, and (6) Technology.

The study has suggested a phase wise recursive KM implementation strategy for Pakistani organizations. We believe the proposed strategy is more pragmatic and operational for handling ontological and epistemological aspects of KM. The proposed approach will offer multifold benefits including monitory benefits, a smooth 
implementation of technology driven KM, to develop a KM culture across the organization, to encourage employees to accept change, and to take appropriate decisions during various implementation phases. Many existing FOSS technologies have been identified which can support the proposed KPs. The study has also made the following recommendations which organizational management can consider for making their KM initiative successful:

Adopt a phase wise recursive implementation approach for $\mathrm{KM}$ initiative.

a. Ensure that $\mathrm{KM}$ vision, mission, goals, objectives, and expectations must be clear to people working at all levels.

b. Take a leadership role through acting as coaches and mentors and demonstrate through their behavior and practices what KM could do to support organizational sustainability, productivity, and competitiveness.

c. Encourage knowledge sharing culture through a better reward system, effective human resource development program and appropriate environment for sharing ideas, experiences and success stories among individuals, teams and external partners.

d. Establishan open and positive communication to share concerns about troubling areas, to learn new skills and experiences from colleagues, to communicate feedback on new initiatives.

e. Encourage creativity, new initiatives, and ownership

f. Overcome the fear of accountability.

\section{REFERENCES}

[1] Nonaka, I. and Takeuchi, H. 1995 The KnowledgeCreating Company. Oxford: Oxford University Press.

[2] Davenport, T. H. and Prusak, L. 1998 Working Knowledge: How Organizations Manage What They Know, Harvard Business School Press, Boston, MA.

[3] Saeed, T., Tayyab, B., Anis-Ul-Haque, M., Ahmad, H. M., and Chaudhry, A. U.2010. Knowledge Management Practices: Role of Organizational Culture, In Proceedings of ASBBS Annual Conference, vol. 17, no. 1, pp.1027-1036.

[4] Quintas, P., Lefrere, P. and Jones, G."Knowledge management: A strategic agenda. Journal of Long Range Planning, Vol.30, No. 3, 1997, pp. 385-391.

[5] Valkokari, K. and Helander, N. "Knowledge management in different types of strategic SME networks", Management Research News, Vol. 30, No. 8, 2007, pp. 597-608.

[6] Salo, N. "The Implications of Knowledge Management Sustainability for Leadership inan Organization: An Exploration and Analysis of Leadership Theories and Knowledge Management Practices in Bangwita Flores, Indonesia", Journal of NTT Studies, Vol. 1, No. 2, 2009, pp. 95-135.

[7] Pasha, M. A. and Pasha, S. 2012. Essentials of Knowledge Management: Concepts, Theories and Practices. Innovators Knowledge Services, Retrieved from http://www.innovators.edu.pk/node/139

[8] Halawi, L. A. , McCarthy, R. V. andAronson, J. E. "An Empirical Investigation of Knowledge Management Systems ' Success", Journal of Computer Information Systems, Vol. 48, No. 3, 2007, pp. 121-136.
[9] Kothari, A., Hovanec, N., Hastie, R. andSibbald, S. "Lessons from the business sector for successful knowledge management in health care: A systematic review", BMC Health Serv Res, Vol. 11, 2011, pp. 173.

[10] Malik, K.P. and Malik, S. "Value Creation Role of Knowledge Management: a Developing Country Perspective",The Electronic Journal of Knowledge Management, Vol. 6, No. 1, 2008, pp. $41-48$

[11] Ali, B. 2008 Critical Success Factors for Effective Knowledge Management in Corporate Sector (Pakistan). Ph. D. Thesis, National University of Modern Languages, Islamabad, Pakistan.

[12] Bano, S., Kashif-ur-Rehman, and Khan, M. A. "Study of Factors that Impact Knowledge Management Fit in Corporate Sector of Pakistan", Far East Journal of Psychology and Business, Vol. 1, No. 1, 2010, pp.1531 .

[13] Abass, F., Hayat, M., Shahzad, A., and Riaz, A. "Analysis of Knowledge Management in the Public Sector of Pakistan", European Journal of Social Sciences, Vol. 19, No. 4, 2011, pp.471-478.

[14] BenMoussa, C. "Barriers to Knowledge Management: A Theoretical Framework and a Review of Industrial Cases, World Academy of Science, Engineering and Technology, Vol. 54, 2009, pp. 906-917.

[15] Creswell, J. W. 2007 Research design: Qualitative, quantitative, and mixed methods approach (2nd ed.). ThousandOaks, CA: Sage Publications.

[16] Alavi, M. and Leidner, D. E. "Review: Knowledge Management and Knowledge Management Systems: Conceptual Foundations and Research Issues", MIS Quarterly, Vol. 25, No. 1, 1999, pp. 107-136.

[17] McQueen, R. 1998. Four Views of Knowledge and Knowledge Management, In Proc. FourthAmericas Conference on Information Systems, Baltimore, Maryland, pp. 609-611.

[18] Carlsson, S. A., El Sawy, O. A., Eriksson, I. and Raven, A. 1996. Gaining Competitive Advantage Through Shared Knowledge Creation: In Search of a New Design Theory for Strategic Information systems, In Proc. Fourth European Conference on Information Systems, Lisbon, Portugal.

[19] Wilson, B. 1984 Systems: Concepts, Methodologies and Applications, John Wiley and Sons, Chichester.

[20] Zack M.H. "Managing codified knowledge", Sloan Management Review, Vo. 40, No. 4, 1999, pp. 45-58.

[21] Andriessen, D. G."Stuff or love; how metaphors direct our efforts to manage knowledge in organizations", Knowledge Management Research and Practice, Vol. 6, 2008, pp.5-12.

[22] Kucza, T. 2001. Knowledge Management Process \& Model, Technical Research Centre Of Finland.

[23] Nonaka, I. "A dynamic theory of organizational knowledge creation", Organization Science, Vol. 5, No. 1, 1994, pp.14-37. 
[24] Huber, G. "Organizational learning: the contributing processes and the literatures", Organization Science, Vol. 2, No. 1, 1991, pp. 88-115.

[25] Sanghani, P. 2009. Knowledge Management Implementation: Holistic Framework Based On Indian Study, In Proceeding of the Pacific Asia Conference on Information Systems.

[26] Bakar, O. 1998 Classification of Knowledge in Islam: A Study in Islamic Philosophies of Science, The American University in Cairo Press.

[27] Polanyi, M. 1966 The Tacit Dimension, Doubleday, Garden City, NY.

[28] Botha, A., Kourie, D. and Snyman, R. 2008Coping with Continuous Change in the Business Environment, Knowledge Management and Knowledge Management Technology, Chandice Publishing Ltd.

[29] Alexander, P. A. and Judy, J. E. "The interaction of domain-specific and strategic knowledge in academic performance", Review of Educational Research, Vol. 58,1988, pp. 375-404.

[30] de Jong, T., and Ferguson-Hessler, M.“Types and qualities of knowledge", Educational Psychologist, Vol. 31, No. 2, 1996, pp. 105- 113.

[31] Granovetter, M."Economic Action and Social Structure: the Problem of Embeddedness", American Journal of Sociology, Vol. 91,1985, pp. 481-93.

[32] Badaracco, J. L. 1991 The Knowledge Link: How Firms Compete Through Strategic Alliances, Boston, MA: Harvard Business School Press.

[33] Blackler, F. “ Knowledge, Knowledge Work and Organizations: An Overview and Interpretation", Organization Studies, Vol. 6, 1995, pp. 1021-1046.

[34] Collins, H. "The structure of knowledge", Social Research, Vol. 60,1993, pp. 95-116.

[35] Wiig, K. M. 2000. Knowledge Management: An Emerging Discipline Rooted in a Long History. In Knowledge Horizons: The Present and the Promise of Knowledge Management, C. Despres and D. Chauvel (Eds.), (pp. 3-26). Boston: Butterworth-Heinemann.

[36] Todd, R. S. and Southon, G. 2000 Knowledge Management: Key to Partnership, In Learning Outcomes and Resourcing a Learning Community. International Association of School Librarianship, pp. 143-154.

[37] Afiouni, F."Human resources management and knowledge management: A road map toward improving organizational performance", Journal of American Academy of Business, Vol. 11, No. 2, 2007.

[38] Prusak, L. 1999. What's up with knowledge management? In The knowledge management yearbook, 1999-2000.J. W. Cortadaand J. A. Woods (Eds.),Boston: Butterworth-Heinemann.

[39] Pee, L. G. and Kankanhalli, A."A Model of Organisational Knowledge Management Maturity Based on People, Process, and Technology", Journal of Information \& Knowledge Management, Vol. 8, No. 2, 2009, pp.79-99.
[40] Dougherty, V. "Knowledge is about people, not databases", Industrial and Commercial Training, Vol. 31, No. 7, 1999, pp.262 - 266.

[41] Edvinsson, L. "Some perspectives on intangibles and intellectual capital", Journal of Intellectual Capital, Vol. 1, No. 1, 2000, pp.12 - 16.

[42] Tannenbaum, S. I., Alliger, G. M. 2000 Knowledge Management: Clarifying the Key Issues, ISBN 0967923913. IHRIM.

[43] Rastogi, P. N. "Knowledge Management and Intellectual Capital - The new virtuous reality of competitiveness", Human Systems Management, Vol. 19, No. 1,2000, pp. 39-49.

[45] Probst, G. 2002Managing Knowledge, Building Blocks for Success. Wiley.West Sussex, England.

[46] Heisig, P., Mertins, K. and Vorbeck J. 2001 Knowledge Management. Concepts and Best practices in Europe $\left(2^{\text {nd }}\right.$ Ed.) Springer-Verlog.Berlin Heidelberg. New York.

[47] McElroy, M. 2002The New Knowledge Management, Complexity, Learning, and Sustainable Innovation. Butterworth-Heineman. Burlington, England.

[48] Anderson, A. and The APQC 1996 The Knowledge Management Assessment Tool, Arthur Anderson and the American Productivity \& Quality Center.

[49] Demarest, M. "Understanding knowledge management", Long Range Planning, Vol. 30, No. 3, 1997, pp. 374-384.

[50] Little, A. D."Knowledge management: reaping the benefits", Prism, Second Quarter, 1998.

[51] Delphi 1998 Delphi on Knowledge Management: Research and Perspectives on Today's Knowledge Landscape, Delphi Group. (www.delphigroup.com).

[52] Wijnhoven, F. "Designing organizational memories: concept and method", Journal of Organizational Computing and Electronic Commerce, Vol. 18, No. 1, 1998, pp. 29-55.

[53] Pan, S., and Scarbrough, H. "A socio-technical view of knowledge-sharing at Buckman laboratories", Journal of Knowledge Management, Vol. 2, No. 1, 1998, pp. $55-66$.

[54] Lee, J. H. and Kim, Y. G. "A stage model of organizational knowledge management: a latent content analysis", Expert Systems with Applications, Vol. 20, 2001, pp. 299-311.

[55] Bhatt, G.D. "Knowledge management in organizations: examining the interaction between technologies, techniques, and people", Journal of Knowledge Management, Vol. 5, No. 1, 2001

[56] Lee, H. and Choi, B. "Knowledge enablers, processes and organizational performance: An integrated view and empirical examination", Journal of Management Information Systems, Vol. 20, No. 1, 2003, pp.179-228.

[57] McInerney, C. R. and Koenig, M. E. D. "Knowledge Management (KM) Processes in Organizations: Theoretical Foundations and Practice", Synthesis Lectures on Information Concepts, Retrieval, and Services, Vol. 3, No. 1, 2011, pp. 1-96. 
[58] Gupta, A.K. and Govindarajan, V. "Knowledge Management's Social Dimension: Lessons From Nucor Steel", Sloan Management Review, Vol. 42, No. 1,2000, pp. 71-81.

[59] Bali, R., Wickramasinghe, N., and Lehaney B. 2009 Knowledge Management Primer, London :Routledge.

[60] McCampbell, A. S., Clare, L.M. and Gitters, S. H."Knowledge management: the new challenge for the 21st century", Journal of Knowledge Management, Vol. 3, No. 3, 1999, pp.172-179.

[61] Claver-Corte's, E., Zaragoza-Sa'ez, P. and PertusaOrtega, E. "Organizational structure features supporting knowledge management processes", Journal of Knowledge Management, Vol.11, No. 4, 2007, pp. 4557.

[62] Al-Mabrouk, K. "Critical Success Factors Affecting Knowledge Management Adoption: A Review of the Literature", Innovations in Information Technology, IEEE Xplore, 2007, pp.1-6.

[63]Martin, B. "Knowledge Management within the Context of Management: An Evolving Relationship", Singapore Management Review, Vol. 22, No. 2,2000, pp. 17-37.

[64] Wenger, E. 1998 Communities of practice: learning, meaning, and identity. Cambridge: Cambridge University Press.
[65] Moon, H. K. and Park, M. S. "Effective Reward Systems for Knowledge Sharing: Facilitating Knowledge Flow at Samsung Life Insurance",Knowledge Management Review, Vol. 4, No. 6, 2002, pp. 22-25.

[66] Brelade, S. and Harman, C. "Using Human Resources to Put Knowledge to Work", Knowledge Management Review, Vol. 3, No. 1,2000, pp. 26-29.

[67] Martin, M., Myers L. A., and Murdock, D. "Facilitating Change Through KM at Premier Inc: Piggy-Backing Knowledge Management Initiatives onto Existing Initiatives", Knowledge Management Review, Vol. 3, No.4, 2000,pp 20-23.

[68] Penrose, E. 1959 The Theory of The Growth of The Firm, Oxford University Press, New York, NY.

[69] Drucker, P. F. 1993 Post-capitalist Society. Oxford: Butterworth-Heinemann.

[70] BenMoussa, C. "Barriers to Knowledge Management: A Theoretical Framework and a Review of Industrial Cases, World Academy of Science", Engineering and Technology, Vol. 54, 2009, pp.906-917.

[71] AMR Research 2007 The Knowledge Management Spending Report,2007-2008. 